\title{
Choosing between anatomy and function is not always evident for the heart of end-stage renal disease patients. How low can we go?
}

\author{
Amalia Peix ${ }^{\mathrm{a}}$ \\ a Nuclear Medicine Department, Institute of Cardiology, La Habana, Cuba
}

Received Mar 23, 2020; accepted Mar 24, 2020

doi: $10.1007 / \mathrm{s} 12350-020-02118-z$

Patients with chronic kidney disease (CKD) are at a very high risk of adverse cardiovascular events. In CKD patients, vascular calcification is more prevalent, appears at an earlier age, and is more severe than in the general population. CKD physiology rather than the effects of dialysis is the primary driver of microvascular disease in these patients. Considering the significant morbidity and mortality attributable to cardiovascular disease in the CKD population, risk stratification remains an important challenge. Topics such as function vs anatomy to properly risk stratify these patients, as well as future perspectives on non-invasive techniques, will be addressed.

Key Words: Cardiovascular disease • chronic kidney disease • coronary artery calcium • carotid plaque burden $\cdot$ myocardial blood flow

See related article, pp. $2660-2670$

\section{HEART, KIDNEY AND THE ROAD TO ATHEROSCLEROSIS}

Patients with chronic kidney disease (CKD) are at a very high risk of adverse cardiovascular events, and those with CKD stages G3a to G4: glomerular filtration rate (GFR) $15-60 \mathrm{~mL} / \mathrm{min} / 1.73 \mathrm{~m}^{2}$ have approximately double and triple cardiovascular disease (CVD) mortality risk, respectively, compared with patients without CKD. ${ }^{1}$ Beyond the presence of traditional cardiovascular risk factors, such as hypertension, diabetes and dyslipidemia, CKD is characterized by an inflammatory state that can be considered as an independent risk factor

Reprint requests: Amalia Peix, Nuclear Medicine Department, Institute of Cardiology, 17 No. 702, Vedado, CP 10400 La Habana, Cuba; atpeix@gmail.com

J Nucl Cardiol 2021;28:2671-5.

$1071-3581 / \$ 34.00$

Copyright (c) 2020 American Society of Nuclear Cardiology. for atherosclerosis. ${ }^{2}$ In addition, CKD is associated with hyperphosphatemia, increased oxidative stress, and a decrease in vascular calcification inhibitors. This favors vascular smooth muscle transformation into osteoblastlike cells, resulting in vascular calcification. ${ }^{3}$

Vascular calcification can occur in the intima and/or the media of blood vessels in multiple vascular beds. ${ }^{4}$ Vascular calcification of the media, also common in diabetes, leads to increased arterial stiffness, increased pulse wave velocity, and left ventricular hypertrophy. Intimal vascular calcification occurs in both the CKD and non-CKD population and it is directly related to atherosclerosis and ischemic heart disease (IHD). ${ }^{3,5}$ In CKD patients, vascular calcification is more prevalent, appears at an earlier age, and is more severe than in the general population. ${ }^{6}$

The medial calcification is considered the more common and major form of calcification in patients with $\mathrm{CKD}^{7}$ and it is constituted by thick hydroxyapatite crystals. $^{8}$

Considering the significant morbidity and mortality attributable to CVD in the CKD population, risk stratification remains an important challenge. To properly risk stratify these patients it is necessary to wisely 
choose between the anatomical and the functional approach.

From the anatomical point of view, coronary artery calcium (CAC) measurement has several advantages, which include an established algorithm, wide availability, and lack of dependence on the operator. There is evidence of a direct correlation between CAC score and obstructive coronary lesions in patients with CKD. ${ }^{9}$ It has been reported an annual average increase in CAC scores of $21 \%$ in men and $18 \%$ in women. ${ }^{10}$ However, in a small study of young patients with end-stage renal disease (ESRD), a mean calcium score rise of 59\% per year has been found, with a doubling of score by 20 months. ${ }^{11}$

On the contrary, measurement of carotid intima-media thickness (cIMT) is operator dependent, requires specialized equipment and training and there is no established algorithm. In the Multiethnic Study of Atherosclerosis in individuals without self-reported CVD, CAC was superior to cIMT for prediction of any incident CVD or any coronary event, while cIMT was a better predictor of stroke. ${ }^{12}$ Of note, since the IMT is a continuous variable, there is no clear upper cutoff value with which to define an atherosclerotic plaque. Normal cIMT has been arbitrarily established as $0.5 \mathrm{~mm}$ to $1.2 \mathrm{~mm}^{13}$; thus, values over $1.1 \mathrm{~mm}$ to $1.2 \mathrm{~mm}$ are considered to define the presence of an atherosclerotic plaque.

In addition, another nice option to consider is the assessment of the carotid plaque burden (cPB) by 3D ultrasound, in order to optimize detection of plaque and to quantify its amount. In the High Risk Plaque BioImage study ${ }^{14}$ the authors presented a new 3D-based ultrasound approach, where the carotid artery was investigated in cross section from proximal in the neck to as distal as possible. From the resulting 10-s video, plaque was outlined on cross-sectional images and all plaque areas were summarized into "plaque burden." In 6101 asymptomatic persons (mean age 68.8 years, 65.3\% with intermediate Framingham Risk Score), carotid plaques were identified in $78 \%$ and CAC in $68 \%$ of participants. Carotid plaque burden was found to correlate stronger with CAC score compared to cIMT, ankle-brachial index, and abdominal aortic diameter. ${ }^{14}$ Nevertheless, in spite of these advantages, cPB is not widespread used yet.

In this issue of the Journal of Nuclear Cardiology, Wenning et al. ${ }^{15}$ studied 39 patients (mean age $53 \pm 12$ years, one-third women) with ESRD prior to kidney transplantation, with the aim of correlating CAC score, $\mathrm{cPB}$, myocardial blood flow (MBF) and coronary flow reserve (CFR). $\mathrm{MBF}$ and $\mathrm{CFR}$ were quantified at baseline and under hyperemia by ${ }^{13} \mathrm{~N}_{-} \mathrm{NH}^{3}-\mathrm{PET} / \mathrm{CT}$. CAC score was calculated from low-dose CT scans acquired for PET attenuation correction (AC), and $\mathrm{CPB}$ was assessed by $3 \mathrm{D}$ ultrasound.
The authors found that while cPB correlated with age $(r=.43 ; P<.01)$, CAC score did not. Neither $\mathrm{CAC}$ nor $\mathrm{CPB}$ correlated with time on dialysis. $\mathrm{MBF}_{\text {stress }}$ was negatively associated with age $(r=.44 ; P<.01)$ and time on dialysis $(r=.42 ; P<.01)$. In addition, negative correlations were shown between $\mathrm{MBF}_{\text {stress }}$ and CAC score $(r=-.62 ; \quad P<.001)$ and between $\mathrm{MBF}_{\text {stress }}$ and $\mathrm{cPB}(r=-.43 ; P<.01)$. Age and CAC score were the strongest predictors for $\mathrm{MBF}_{\text {stress. }}$. No significant correlation was identified between CFR and CAC score $(r=-.2 ; P=0.91)$ or between CFR and $\mathrm{cPB}(r=-.1 ; P=0.55)$. Interestingly, cardiovascular event-free survival was associated with reduced CFR and $\operatorname{MBF}_{\text {stress }}(P=0.001$ and $P<.001)$, but not with $\mathrm{CPB}$ or $\mathrm{CAC}$ score. ${ }^{15}$

In their study, Wenning et al concluded that CAC score, $\mathrm{cPB}$ and $\mathrm{MBF}_{\text {stress }}$ are associated in patients with ESRD. Considering that cardiovascular event-free survival is associated with impaired CFR and $\mathrm{MBF}_{\text {stress }}$, but not with the presence of calcium or plaque burden, quantitative MPI cannot be replaced by the assessment of CAC score or cPB only. ${ }^{15}$ This is an interesting conclusion, because previous investigations state that risk of cardiac events and CVD in ESRD patients is predicted independently by CAC. ${ }^{16-19}$

The ACCF/AHA 2007 Clinical Expert Consensus Document on coronary artery calcium scoring by computed tomography in global cardiovascular risk assessment ${ }^{20}$ recommended that ESRD patients be placed in the "highest risk" category and therefore receive aggressive preventive therapies. ${ }^{20}$ It has been shown a remarkably high prevalence of CAC in patients with ESRD who are undergoing dialysis, especially in young adults compared with controls. ${ }^{11}$ But the consensus considered that the role of CAC score in determining risk in patients with CKD and/or ESRD was unclear due to a limited number of clinical studies in these populations. This situation continues at present, mainly due to the limited number of CKD cases included in prospective investigations.

Although some studies have indicated cIMT as a predictor of cardiovascular events in patients undergoing hemodialysis, ${ }^{21,22}$ Wenning et al did not use cIMT as one of the non-invasive techniques to assess cardiovascular risk. Of note, cIMT usefulness is somewhat controversial, because in spite of its correlation with the presence of CAC, other authors have not found a relationship with cardiovascular events. ${ }^{23,24}$

Another factor to consider in risk stratifying is vascular aging. Aging is the main risk factor for vascular disease and the resulting cardiovascular and cerebrovascular events. Vascular aging leads to arterial degeneration and hardening that impairs vascular function, causing end organ damage, mainly in the heart, 
brain, and kidney. ${ }^{25}$ Whereas chronological aging refers only to the passage of time, biological aging relates to decline in function and can be accelerated in certain diseases such as type 2 diabetes, CKD, autoimmune diseases, human immunodeficiency virus infection, and several genetic diseases. Biological vascular age should be used to select individuals for early prevention of CVD and can be estimated using molecular and cellular biomarkers (in blood, urine, or feces), functional and structural vascular parameters (measured by non-invasive techniques), or a combination of both. ${ }^{25}$

In their study, Wenning et al acknowledged the small sample size as a limitation of their study, which is real, as well as the relatively young age and short time of dialysis of their patients, which may explain the relatively low numbers of cardiovascular events. ${ }^{15}$ Theirs was rather a descriptive approach and did not make possible to obtain predictive information.

It is necessary to remember that the most important value of diagnostic methods is not the diagnosis itself, but the prognostic information which offer. This means, the capacity of the test to predict patient's evolution and guide the management. Thus, comparative effectiveness research of imaging techniques assesses the degree to which an imaging test can confer clinically significant improvement in therapeutic decision-making and patient outcome.

In Wenning's study, a nice comparison among different imaging techniques providing anatomical and functional information is shown. However, new researches are necessary to clarify how clinicians can choose between anatomical and functional tests in order to provide the best risk stratification for IHD in ESRD patients to adequately guide management. Imaging does not directly affect outcome itself, it rather affects the management decisions that may result in a positive outcome.

To assess CAC and with the aim of reducing radiation dose, the authors chose the non-ECG triggered, low-dose CT used for attenuation correction. But, in spite of the fact that this option is feasible, ${ }^{26,27}$ and that they did not intend to obtain an exact CAC score but rather a measure of the extent of coronary artery calcification, other studies have shown still controversial results, considering that $\mathrm{CAC}$ score calculation on the basis of an AC-CT is not as exact as a calcium scoring CT due to motion artifacts and blurring of the coronary arteries or partial volume effect, mostly leading to an underestimation of CAC scores. ${ }^{28}$

Regarding the functional approach offered by PET MPI, Charytan et al. ${ }^{29}$ reported that CFR is strongly associated with cardiovascular risk regardless of CKD severity. CFR is low in early stage CKD without further decrement in stage 5 or dialysis-dependent CKD, suggesting that CKD physiology rather than the effects of dialysis is the primary driver of microvascular disease, with the contribution of microvascular dysfunction to cardiovascular risk in CKD. ${ }^{29,30}$

Wenning et al considered that due to the high negative predictive value of low $\mathrm{CPB}$ and low CAC for a preserved CFR (and consequently exclusion of significant CAD), MPI may not be necessary in cases of normal findings in carotid ultrasound and no CAC. On the contrary, abnormal carotid ultrasound and CAC score may potentially serve as a gatekeeper for functional ischemia imaging. ${ }^{15}$ In this case, MPI with PET may be a better option than SPECT considering the possibility of MBF and CFR assessment.

\section{FUTURE PERSPECTIVES}

It is well known that ESRD patients have a higher mortality due to CVD than the general population. Studies suggest that there are significant opportunities to improve treatment of established risk factors, and Kidney Disease: Improving Global Outcomes (KDIGO) Group guidelines for the care of kidney transplant recipients ${ }^{31}$ and for lipid management in $\mathrm{CKD}^{32}$ provide specific treatment recommendations. Thus, an adequate risk stratification able to influence the decision-making process on an individual basis is of crucial importance. Some aspects may be considered as future perspectives:

- More prospective studies are needed to assess the value of non-invasive techniques (anatomical $v s$. functional) to influence the decision-making process.

- Chen et al. ${ }^{33}$ found that in female, but not in male, lower bone mineral density (BMD), in particular in subregions of legs, was independently associated with higher CAC score, as well as low BMD has the potential to identify increased risk for high CAC score in ESRD patients. So, considering that the independent inverse association between BMD and CAC observed in females may suggest that the link between arterial calcification and bone mineralization is mediated by sex hormones, it is necessary a further comparison between sexes, including hormonal status.

- Whereas some adjustment may improve the performance of standard cardiac risk assessment methods in early stage CKD, standard risk prediction methods function poorly in patients with ESRD. ${ }^{34}$ ESRD appears to modify the effects of standard risk factors (hypercholesterolemia, blood pressure, and high glucose), and the increased rates of sudden death and heart failure are not apprehended by standard risk methods in these patients. Entirely new cardiovascular risk models may be needed in ESRD. Sarnack et al. ${ }^{1}$ propose to assess the utility of novel risk markers to improve prediction (e.g., 
coronary calcification, cTnT, BNP, troponins, and markers of $\mathrm{Ca} / \mathrm{P}$ metabolism), in addition to $\mathrm{CKD}$ specific terms such as estimated GFR (eGFR) and albumin-to-creatinine ratio, based on individual patient data and the development and validation of ESRDspecific CVD risk prediction scores. ${ }^{1,35}$

- Regarding functional non-invasive evaluation, although SPECT MPI is a valuable tool to detect stress-inducible ischemia, it is not so useful to assess microvascular dysfunction. So, absolute MBF provided by PET may further refine risk prediction. CFR provides information on both coronary atherosclerosis and small vessel function and may be a particularly powerful prognostic tool.

- Other alternatives offered by PET should be explored, such as: ${ }^{18} \mathrm{~F}-\mathrm{NaF}$ and ${ }^{18} \mathrm{~F}-\mathrm{FDG}$ PET/CT imaging. ${ }^{18} \mathrm{~F}$ $\mathrm{NaF}$ PET has been shown to be useful for the identification of early active calcification and microcalcification, ${ }^{36}$ which makes it potentially useful for the identification of vulnerable plaques ${ }^{37}$ and individuals with high CVD risk. ${ }^{38,39}$ On the other hand, ${ }^{18} \mathrm{~F}$ FDG PET/CT is capable of quantifying atherosclerotic inflammation, predicting subsequent cardiovascular events ${ }^{40}$ and providing a means of evaluating changes with treatment. ${ }^{41}$ However, ${ }^{18} \mathrm{~F}$ FDG, in contrast to ${ }^{18} \mathrm{~F}-\mathrm{NaF}$, is limited for the assessment of coronary arteries because of myocardial spillover in spite of significant efforts at background myocardial suppression. ${ }^{38}$

\section{CONCLUSIONS}

The association of CKD with CAD is driven by a high prevalence of traditional as well as uremia-related IHD risk factors. Anatomical non-invasive tests such as CAC score, cIMT or cPB may serve as a gatekeeper to MPI functional evaluation of ischemia/microvascular dysfunction and ulterior coronary angiography if needed. An adequate risk stratification able to influence the decision-making process on an individual basis is of crucial importance in ESRD patients.

\section{Disclosure}

A. Peix has nothing to declare.

\section{References}

1. Sarnak MJ, Amann K, Bangalore S, Cavalcante JL, Charytan DM, Craig JC, et al. Chronic kidney disease and coronary artery disease. J Am Coll Cardiol 2019;74:1823-38.

2. Lemos MM, Jancikic AD, Sanches FM, Christofalo DM, Ajzen $\mathrm{SA}$, Carvalho $\mathrm{AB}$, et al. Intima-media thickness is associated with inflammation and traditional cardiovascular risk factors in nondialysis-dependent patients with chronic kidney disease. Nephron Clin Pract 2010;115:c189-94.
3. Adeseun GA, Xie D, Wang X, Joffe MM, Mohler ER, Townsend $\mathrm{RR}$, et al. Carotid plaque, carotid intima-media thickness, and coronary calcification equally discriminate prevalent cardiovascular disease in kidney disease. Am J Nephrol 2012;36:342-7.

4. London GM, Guerin AP, Marchais SJ, Metivier F, Pannier B, Adda $\mathrm{H}$. Arterial media calcification in end-stage renal disease: Impact on all-cause and cardiovascular mortality. Nephrol Dial Transplant 2003;18:1731-40.

5. Nakamura S, Ishibashi-Ueda H, Niizuma S, Yoshihara F, Horio T, Kawano Y. Coronary calcification in patients with chronic kidney disease and coronary artery disease. Clin J Am Soc Nephrol 2009;4:1892-900

6. Nolan RL, Morton AR, Pickett W. Prevalence and associations of coronary artery calcification in patients with stages 3 to $5 \mathrm{CKD}$ without cardiovascular disease. Am J Kidney Dis 2008;52:849-58.

7. Cardellini M, Rovella V, Scimeca M, Anemona L, Bischetti S, Casella $\mathrm{S}$, et al. Chronic kidney disease is linked to carotid nodular calcification, an unstable plaque not correlated to inflammation. Aging Dis 2019;10:71-81.

8. Schlieper G, Aretz A, Verberckmoes SC, Krüger T, Behets GJ, Ghadimi R, et al. Ultrastructural analysis of vascular calcifications in uremia. J Am Soc Nephrol 2010;21:689-96.

9. Robinson J, Tan AU, Wilensky RL, Matthai W, Munoz M, Rosas SE. Electron-beam computerized tomography correlates with coronary angiogram in chronic kidney disease patients. Am J Nephrol 2007;27:247-52.

10. Budoff MJ. Screening for ischemic heart disease with cardiac CT: Current recommendations. Scientifica (Cairo) 2012;2012:812046. https://doi.org/10.6064/2012/812046.

11. Goodman WG, Goldin J, Kuizon BD, Yoon C, Gales B, Sider D, et al. Coronary-artery calcification in young adults with end-stage renal disease who are undergoing dialysis. $\mathrm{N}$ Engl $\mathrm{J}$ Med 2000;342:1478-83.

12. Folsom AR, Kronmal RA, Detrano RC, O'Leary DH, Bild DE, Bluemke DA, et al. Coronary artery calcification compared with carotid intima-media thickness in the prediction of cardiovascular disease incidence: The Multi-Ethnic Study of Atherosclerosis (MESA). Arch Intern Med 2008;168:1333-9.

13. Spacil J, Ceska R, Petrasek J, Sobra J. The effect of four-year hypolipidaemic treatment on the intimal thickness of the common carotid artery in patients with familiar hyperlipidaemia. Int Angiol 1999;18:313-9.

14. Sillesen H, Muntendam P, Adourian A, Entrekin R, Garcia M, Falk E, et al. Carotid plaque burden as a measure of subclinical atherosclerosis: Comparison with other tests for subclinical arterial disease in the high risk plaque BioImage Study. J Am Coll Cardiol Img 2012;5:681-9.

15. Wenning C, Vrachimis A, Pavenstädt HJ, Reuter S, Schäfers M. Coronary artery calcium burden, carotid atherosclerotic plaque burden and myocardial blood flow patients with end-stage renal disease: A non-invasive imaging study combining PET/CT and 3D-ultrasound. J Nucl Cardiol 2020. https://doi.org/10.1007/s123 50-020-02080-w.

16. Matsuoka M, Iseki K, Tamashiro M, Fujimoto N, Higa N, Touma $\mathrm{T}$, et al. Impact of high coronary artery calcification score (CACS) on survival in patients on chronic hemodialysis. Clin Exp Nephrol 2004;8:54-8.

17. Block GA, Raggi P, Bellasi A, Kooienga L, Spiegel DM. Mortality effect of coronary calcification and phosphate binder choice in incident hemodialysis patients. Kidney Int 2007;71:438-41.

18. Detrano R, Guerci AD, Carr JJ, Bild DE, Burke G, Folsom AR, et al. Coronary calcium as a predictor of coronary events in four racial or ethnic groups. N Engl J Med 2008;358:1336-45. 
19. Greenland P, LaBree L, Azen SP, Doherty TM, Detrano RC. Coronary artery calcium score combined with Framingham score for risk prediction in asymptomatic individuals. JAMA 2004;291:210-5.

20. Greenland P, Bonow RO, Brundage BH, Budoff MJ, Eisenberg MJ, Grundy SM, et al. ACCF/AHA 2007 clinical expert consensus document on coronary artery calcium scoring by computed tomography in global cardiovascular risk assessment and in evaluation of patients with chest pain: A report of the American College of Cardiology Foundation Clinical Expert Consensus Task Force (ACCF/AHA Writing Committee to Update the 2000 Expert Consensus Document on Electron Beam Computed Tomography) developed in collaboration with the Society of Atherosclerosis Imaging and Prevention and the Society of Cardiovascular Computed Tomography. J Am Coll Cardiol 2007;49:378-402.

21. Kato A, Takita T, Maruyama Y, Kumagai H, Hishida A. Impact of carotid atherosclerosis on long-term mortality in chronic hemodialysis patients. Kidney Int 2003;64:1472-9.

22. Ekart R, Hojs R, Hojs-Fabjan T, Balon BP. Predictive value of carotid intima media thickness in hemodialysis patients. Artif Organs 2005;29:615-9.

23. Zoungas S, Cameron JD, Kerr PG, Wolfe R, Muske C, McNeil JJ, et al. Association of carotid intima-medial thickness and indices of arterial stiffness with cardiovascular disease outcomes in CKD. Am J Kidney Dis 2007;50:622-30.

24. Gaspar A, Watanabe R, Montebello M, Fernandes ME. Evaluation of intima-media thickness in patients with chronic kidney disease not on dialysis: A prospective study of 24 months. J Bras Nefrol 2014;36:35-41.

25. Hamczyk MR, Nevado RM, Barettino A, Fuster V, Andrés V. Biological versus chronological aging. J Am Coll Cardiol 2020;75:919-30.

26. Einstein AJ, Johnson LL, Bokhari S, Son J, Thompson RC, Bateman TM, et al. Agreement of visual estimation of coronary artery calcium from low-dose CT attenuation correction scans in hybrid PET/CT and SPECT/CT with standard Agatston score. J Am Coll Cardiol 2010;56:1914-21.

27. Xie X, Zhao Y, de Bock GH, de Jong PA, Mali WP, Oudkerk M, et al. Validation and prognosis of coronary artery calcium scoring in nontriggered thoracic computed tomography: Systematic review and meta-analysis. Circ Cardiovasc Imaging 2013;6:514-21.

28. Dumer S, Einstein A. Coronary calcium scoring of CT attenuation correction scans: Automatic, manual, or visual? J Nucl Cardiol 2018;25:2144-7.

29. Charytan DM, Skali H, Shah NR, Veeranna V, Cheezum MK, Taqueti VR, et al. Coronary flow reserve is predictive of the risk of cardiovascular death regardless of chronic kidney disease stage. Kidney Int 2018;93:501-9.

30. Murthy VL, Naya M, Foster CR, Hainer J, Gaber M, Dorbala S, et al. Coronary vascular dysfunction and prognosis in patients with chronic kidney disease. JACC Cardiovasc Imaging 2012;5:102534.

31. Kidney Disease: Improving Global Outcomes Transplant Work Group. KDIGO clinical practice guideline for the care of kidney transplant recipients. Am J Transplant 2009;9:S1-155.

32. Kidney Disease: Improving Global Outcomes (KDIGO) Lipid Work Group. KDIGO clinical practice guideline for lipid management in chronic kidney disease. Kidney Int Suppl 2013;3:259305 .

33. Chen Z, Qureshi AR, Brismar TB, Ripsweden J, Haarhaus M, Barany $\mathrm{P}$, et al. Differences in association of lower bone mineral density with higher coronary calcification in female and male endstage renal disease patients. BMC Nephrol 2019;20:59. https://doi. org/10.1186/s12882-019-1235-z.

34. Anker SD, Gillespie IA, Eckardt KU, Kronenberg F, Richards S, Drueke TB, for the ARO Steering Committee, et al. Development and validation of cardiovascular risk scores for haemodialysis patients. Int J Cardiol 2016;216:68-77.

35. Valdivielso JM, Rodríguez-Puyol D, Pascual J, Barrios C, Bermúdez-López M, Sánchez-Niño MD, et al. Atherosclerosis in chronic kidney disease: More, less, or just different? Arterioscler Thromb Vasc Biol 2019;39:1938-66.

36. Fiz F, Morbelli S, Piccardo A, Bauckneht M, Ferrarazzo G, Pestarino E, et al. 18F-NaF uptake by atherosclerotic plaque on PET/ CT imaging: Inverse correlation between calcification density and mineral metabolic activity. J Nucl Med 2015;56:1019-23.

37. Rosa GM, Bauckneht M, Masoero G, Mach F, Quercioli A, Seitun $\mathrm{S}$, et al. The vulnerable coronary plaque: Update on imaging technologies. Thromb Haemost 2013;110:706-22.

38. Joshi NV, Vesey AT, Williams MC, Shah AS, Calvert PA, Craighead $\mathrm{FH}$, et al. 18F-fluoride positron emission tomography for identification of ruptured and high-risk coronary atherosclerotic plaques: A prospective clinical trial. Lancet 2014;383:70513.

39. Wang Y, Osborne MT, Tung B, Li M, Li Y. Imaging cardiovascular calcification. J Am Heart Assoc 2018;7:e008564. https://doi. org/10.1161/JAHA.118.008564.

40. Figueroa AL, Abdelbaky A, Truong QA, Corsini E, MacNabb $\mathrm{MH}$, Lavender ZR, et al. Measurement of arterial activity on routine FDG PET/CT images improves prediction of risk of future CV events. JACC Cardiovasc Imaging 2013;6:1250-9.

41. Fayad ZA, Mani V, Woodward M, Kallend D, Abt M, Burgess T, dal- PLAQUE Investigators, et al. Safety and efficacy of dalcetrapib on atherosclerotic disease using novel non-invasive multimodality imaging (dal-PLAQUE): A randomised clinical trial. Lancet 2011;378:1547-59.

Publisher's Note Springer Nature remains neutral with regard to jurisdictional claims in published maps and institutional affiliations. 